Unnes Journal of Public Health

\title{
EVALUASI PENERAPAN ABg (AKTIF BERBAGI) SISTEM SEBAGAI UPAYA MENGURANGI ANGKA KECELAKAAN KERJA DI PT. COCA-COLA AMATIL INDONESIA CENTRAL JAVA
}

\author{
Asep Alvan ${ }^{凶}$, Evi Widowati
}

Jurusan Ilmu Kesehatan Masyarakat, Fakultas Ilmu Keolahragaan, Universitas Negeri Semarang, Indonesia

\begin{abstract}
Info Artikel
Sejarah Artikel:

Diterima September 2015

Disetujui September 2015

Dipublikasikan Januari 2016

Keywords:

ABg (Aktif Berbagi) System; Occupational Health and Safety (OHS)

Abstrak

PT. Coca-Cola Amatil Indonesia Central Java (CCAI-CJ) pada tahun 2013 telah menerapkan program ABg (Aktif Berbagi) Sistem, pada tahun tersebut terdapat peningkatan kasus kecelakaan kerja di area kerja dari tahun sebelumnya sebanyak 2 kasus. Tujuan penelitian ini adalah untuk mengetahui gambaran evaluasi dan rekomendasi dari kendala-kendala dalam penerapan ABg Sistem sebagai upaya mengurangi angka kecelakaan kerja di PT. CCAI-CJ. Jenis penelitian ini adalah penelitian kualitatif dengan menggunakan pendekatan etnografi. Teknik pengambilan sumber informasi yang digunakan adalah teknik snowball sampling, jumlah informan awal yaitu dua orang. Hasil penelitian didapatkan masih terdapat kendala dalam penerapan ABg Sistem yaitu: pelaksanaan pengawasan Keselamatan dan Kesehatan Kerja (K3) yang belum berjalan konsisten. Konsistensi penerapan peraturan dan prosedur K3 yang belum optimal serta adanya sanksi yang tidak sesuai dengan prosedur penerapan $\mathrm{ABg}$ Sistem. Kurangnya komunikasi antara manajemen dengan pekerja dan kurangnya pemahaman pekerja tentang informasi K3. Kurangnya keterlibatan pekerja dalam pelaporan kejadian kecelakaan/kondisi berbahaya. Saran yang dapat diberikan yaitu: konsistensi pelaksanaan pengawasan K3 sesuai prosedur, sanksi yang diberikan lebih baik berupa arahan bagi pekerja untuk dapat bekerja lebih aman, melakukan komunikasi kepada pekerja sesuai dengan prosedur komunikasi internal, diadakan peningkatan kompetensi melalui pelatihan awareness $\mathrm{K} 3$, serta dilakukan pelatihan mengenai prosedur pelaporan kecelakaan/kondisi berbahaya kepada pekerja.
\end{abstract}

\section{Abstract}

PT. Coca-Cola Amatil Indonesia Central Java (CCAI-CJ) in 2013 has implemented ABg (Aktif Berbagi) system program, there are two accident cases increase in 2013 at the working areas. The purpose of this study is to describe the evaluation and recommendation of the constraints in the implementation of ABg System as an effort to reduce the number of accidents in the workplace. This research design is a qualitative study which an ethnographic approach. Retrieval techniques used resources is snowball sampling technique, the amount of the initial informant that two people. The result showed that the application of ABg System, such as monitoring the implementation of the Occupational Health and Safety (OHS) which have not been running consistently yet. Consistency of application of rules and procedures OHS have not been optimal as well as the punishment that have not in accordance with the procedures for application of ABg System. Lack of communication between management and workers and workers' understanding of the OHS information. Lack of worker involvement in the reporting of accidents/dangerous conditions. The suggestions are: the consistency of supervision OHS according to the procedure, the better the sanctions provided as suggestion to the working to work safely, communicating to the employees in accordance with the procedures of internal communication, held competency improvement through awareness training OHS, and conducted training on reporting procedures accident/unsafe conditions to workers.

(C) 2016 Universitas Negeri Semarang

\footnotetext{
Alamat korespondensi:

Gedung F1 Lantai 2 FIK Unnes

Kampus Sekaran, Gunungpati, Semarang, 50229

E-mail: asep.alvan.tapsir@gmail.com
}

ISSN 2252-6528 


\section{PENDAHULUAN}

Kecelakaan kerja adalah suatu kejadian yang jelas tidak dikehendaki dan sering kali tidak terduga semula yang dapat menimbulkan kerugian baik waktu, harta benda atau properti maupun korban jiwa yang terjadi di dalam suatu proses kerja industri atau yang berkaitan dengannya (Tarwaka, 2008:5). Berdasarkan Heinrich (1959) pada teori urutan domino (domino sequence) melaporkan bahwa terjadinya kecelakaan kerja disebabkan $88 \%$ oleh karena unsafe acts of persons, $10 \%$ unsafe condition dan $2 \%$ oleh sebab-sebab lain yang tidak dapat dipelajari (Winarsunu $\mathrm{T}$, 2008:7).

Berdasarkan data dari U.S. Bureau of Labor Statistics, U.S. Department of Labor tahun 2013 didapat data kecelakaan kerja pada tahun 2010 dengan total kecelakaan kerja sebanyak 4.690 kasus. Dari 4.690 kasus kecelakaan kerja tersebut 329 kasus (7\%) terjadi di industri manufaktur. Sedangkan pada tahun 2011 total kecelakaan kerja mencapai 4.693 kasus, dengan kasus kecelakaan kerja di industri manufaktur sebesar 327 kasus (6,9\%). Dan pada tahun 2012 total kasus kecelakaan kerja mencapai 4.383 kasus, dengan 314 kasus $(7,2 \%)$ terjadi di industri manufaktur.

Berdasarkan data Health and Safety Executive tahun 2013 di Negara Inggris total kecelakaan kerja mencapai 78.321 kasus. Dari total kasus kecelakaan kerja tersebut manufacturing industries menyumbangkan angka kecelakaan kerja sebesar 13.731 kasus $(17,5 \%)$, pada manufacture of beverage (industri minuman) menyumbang angka kecelakaan kerja sebesar 248 kasus $(0,3 \%)$ dari total kasus kecelakaan kerja yang ada. Kecelakaan kerja tersebut mengakibatkan 148 pekerja meninggal di tempat kerja, hilangnya hari kerja sebanyak 27 juta hari kerja, dan kerugian material mencapai 274 triliun rupiah.

Kecelakaan kerja di Indonesia berdasarkan data dari PT. Jamsostek menyebutkan bahwa pada tahun 2011 telah terjadi 99.491 kasus kecelakaan kerja. Sedangkan pada tahun 2012 angka kecelakaan kerja mengalami kenaikan dibandingkan pada tahun 2011. Jumlah total kecelakaan kerja pada tahun 2012 sebanyak 103.074 kecelakaan kerja.

Data kecelakaan kerja berdasarkan Disnakertrans pada tahun 2012 tercatat Provinsi Jawa Tengah menyumbangkan kasus kecelakaan kerja sebanyak 5.029 kasus. Sedangkan data mengenai kecelakaan kerja di Kabupaten Semarang menurut Kepala Dinas Sosial Tenaga Kerja dan Transmigrasi melalui Kepala Bidang Pembinaan Hubungan Industrial dan Pengawasan Ketenagakerjaan tercatat tahun 2013 terjadi 840 kasus kecelakaan kerja dengan kerugian materi mencapai 3,29 miliar rupiah. Dari 840 kasus kecelakaan tersebut, 339 pekerja $(40,4 \%)$ berhasil sembuh, 469 pekerja (55,8\%) sementara tidak mampu bekerja, 15 pekerja $(1,8 \%)$ mengalami cacat, dan 17 pekerja (2\%) meninggal dunia.

Berdasarkan data Global Reporting Initiative (GRI) Coca-Cola Company tahun 2012, melaporkan bahwa tahun 2010 dengan jumlah pekerja 139.600 pekerja, kehilangan hari kerja sebanyak 185.605 hari kerja, sedangkan tahun 2011 dengan jumlah pekerja 139.600 pekerja, kehilangan hari kerja sebanyak 108.766 hari kerja. Hilangnya hari kerja pada tahun 2011 disebabkan oleh terjadinya kecelakaan kerja yang mengakibatkan 12 pekerja meninggal.

Berdasarkan data kecelakaan kerja yang diberikan oleh PT. Coca-Cola Amatil 
Indonesia Central Java periode 2011-2013 terdapat 48 kasus kecelakaan kerja. Pada tahun 2011 yaitu sebelum diterapkannya ABg (Aktif Berbagi) Sistem terdapat 12 kasus kecelakaan kerja dengan 5 kasus $(41,6 \%)$ terjadi di perjalanan dan 7 kasus $(58,4 \%)$ hubungan kerja. Sedangkan pada tahun 2012 jumlah kasus kecelakaan kerja sebanyak 23 kasus dengan 9 kasus $(39,1 \%)$ terjadi di perjalanan dan 14 kasus $(60,9 \%)$ hubungan kerja, tahun 2012 ini adalah tahun dimana mulai disosialisasikannya ABg sistem. Dan pada tahun 2013 yaitu mulai di terapkannya $\mathrm{ABg}$ sistem di seluruh area kerja, terjadi penurunan kasus kecelakaan kerja dibandingkan tahun 2012 yaitu sebanyak 13 kasus kecelakaan kerja dengan 6 kasus $(46,1 \%)$ terjadi di perjalanan, 5 kasus $(38,5 \%)$ hubungan kerja, dan 2 kasus $(15,4 \%)$ terjadi di area kerja. Pada tahun 2013 tersebut terjadi kenaikan kecelakaan kerja di area kerja sebanyak 2 kasus kecelakaan kerja yang pada dua tahun sebelumnya tidak terdapat kecelakaan di area kerja. Kasus kecelakaan kerja pada tahun 2013 tersebut mengakibatkan hilangnya hari kerja sebanyak 9 hari dan kerugian mencapai 32,6 juta rupiah (Dokumen OHS-CCAI Central Java, 2013).

Berdasarkan jurnal yang meneliti tentang safety culture, ada beberapa indikator yang dapat mendukung terciptanya safety culture di perusahaan/industri. Indikator tersebut diantaranya adalah komitmen top manajement, peraturan dan prosedur $\mathrm{K} 3$, komunikasi pekerja, kompetensi pekerja, lingkungan kerja, dan keterlibatan pekerja. Dari enam indikator tersebut, keterlibatan pekerja merupakan indikator dominan yang digunakan untuk menciptakan safety culture di perusahaan/industri. Keterlibatan pekerja merupakan komponen penting untuk menciptakan safety behavior dan safety condition di tempat kerja. (Wieke Yuni dkk, 2012:83; Andi dkk, 2005:127).

Pada PT. Coca-Cola Amatil Indonesia Central Java, penerapan budaya K3 (safety culture) dikembangkan melalui salah satu sistem yang di terapkan oleh Departemen Occupational Health and Safety (OHS). Sistem tersebut adalah "Aktif Berbagi Sistem" atau biasa disebut $\mathrm{ABg}$ sistem. $\mathrm{ABg}$ sistem di rancang pada tahun 2011 oleh pihak Coca-Cola Amatil Indonesia (CCAI) pusat di Jakarta yang berlandaskan dari DuPont Stop System kemudian dikembangkan untuk menjadi sistem budaya K3 di CCAI. ABg sistem hanya diterapkan di area produksi saja, hal tersebut dikarenakan area produksi merupakan area yang berada di dalam perusahaan sehingga dapat lebih mudah diawasi secara langsung oleh Departemen OHS. Maksud dari adanya ABg sistem ini yaitu mencegah terjadinya luka dan sakit di tempat kerja, menciptakan tempat kerja yang aman, mengatasi semua tindakan tidak aman dan kondisi tidak aman, serta menekan angka kecelakan kerja di area kerja untuk menciptakan kondisi zero accident di tempat kerja (OHS-CCAI Central Java, 2013).

Berdasarkan uraian di atas, peneliti tertarik untuk melakukan penelitian bagaimana evaluasi penerapan $\mathrm{ABg}$ (Aktif Berbagi) sistem yang digunakan sebagai salah satu upaya untuk mengurangi angka kecelakaan kerja di PT. Coca-Cola Amatil Indonesia Central Java".

\section{METODE}

Penelitian ini menggunakan metode penelitian kualitatif dengan rancangan penelitian yang digunakan adalah interpretive dan pendekatan etnografi. Teknik pengambilan informan secara 
snowball sampling, yaitu teknik pengambilan sampel sumber data yang pada awalnya jumlahnya sedikit, lama-lama menjadi besar. Hal ini dilakukan karena dari jumlah sumber data yang sedikit tersebut belum mampu memberikan data yang lengkap, maka mencari sumber informasi lain yang dapat digunakan sebagai sumber data (Sugiono, 2010: 300). Informan awal pada penelitian ini berjumlah dua informan dan informan lanjutan pada penelitian ini berjumlah empat informan. Kriteria informan pada penelitian ini yaitu mereka yang menguasai dan memahami program $\mathrm{ABg}$ sistem serta terlibat dalam kegiatan $\mathrm{ABg}$ sistem.

Pengumpulan data dilakukan dengan cara wawancara mendalam, observasi, dan studi dokumen. Alat bantu yang digunakan dalam pengumpulan data adalah panduan wawancara mendalam, lembar observasi, alat perekam, dan kamera. Uji keabsahan data dilakukan dengan teknik triangulasi, yaitu dengan cara membandingkan data hasil observasi dengan hasil wawancara, membandingkan jawaban yang diberikan informan satu dengan informan lain, dan membandingkan hasil wawancara dengan isi suatu dokumen yang terkait. Teknik analisis data yang digunakan dalam penelitian ini adalah teknik analisis data model Miles and Huberman. Aktivitas dalam analisis data menurut Miles and Huberman yaitu, Reduksi Data (Data Reduction), Sajian Data (Data Display), dan Penarikan Kesimpulan dan Verifikasi (Conclusion Drawing/Verification) (Sugiono, 2010: 335).

\section{HASIL DAN PEMBAHASAN}

\section{Karakteristik Informan Penelitian}

Informan dalam penelitian ini di bagi menjadi dua, yaitu informan awal dan informan lanjutan. Karakteristik informan dalam penelitian ini disajikan pada Tabel 1 dan Tabel 2 berikut ini:

Tabel 1. Karakteristik Informan Awal

\begin{tabular}{lllllll}
\hline \hline $\begin{array}{l}\text { No. } \\
\text { Infor- } \\
\text { man }\end{array}$ & Jabatan & $\begin{array}{l}\text { Jenis } \\
\text { Kelamin } \\
(\mathrm{L} / \mathrm{P})\end{array}$ & $\begin{array}{l}\text { Umur } \\
\text { (Tahun) }\end{array}$ & $\begin{array}{l}\text { Pendidikan } \\
\text { Terakhir }\end{array}$ & $\begin{array}{l}\text { Masa } \\
\text { (Tahun) }\end{array}$ & Kerja \\
1. & OHS Manager & $\mathrm{L}$ & 44 & D3 Teknik Mesin & 15 & \\
2. & OHS Officer & $\mathrm{L}$ & 39 & D3 Ekonomi & 12 & \\
\hline
\end{tabular}

Tabel 2. Karakteristik Informan Lanjutan

\begin{tabular}{lllllll}
\hline \hline $\begin{array}{l}\text { No. } \\
\text { Infor- } \\
\text { man }\end{array}$ & Jabatan & $\begin{array}{l}\text { Jenis } \\
\text { Kelamin } \\
\text { (L/P) }\end{array}$ & $\begin{array}{l}\text { Umur } \\
\text { (Tahun) }\end{array}$ & $\begin{array}{l}\text { Pendidikan } \\
\text { Terakhir }\end{array}$ & $\begin{array}{l}\text { Masa } \\
\text { (Tahun) }\end{array}$ & Kerja \\
3. & $\begin{array}{l}\text { Supervisor Produksi } \\
\text { (Water Syrup) }\end{array}$ & $\mathrm{L}$ & 40 & SMA & 30 & \\
& Line Crew & $\mathrm{L}$ & 30 & SMA & 5 & \\
4. & Inspector Line 8 & $\mathrm{~L}$ & 30 & SMA & 13 & \\
5. & Lacker Crew & L & 37 & SMA & 18 & \\
6. & & & & &
\end{tabular}

Informan awal dalam penelitian ini departemen Occupational Health and Safety diambil dari pihak manajemen yaitu (OHS) yang berjumlah dua informan. 
Sedangkan untuk informan lanjutan dalam penelitian ini berjumlah empat informan dengan satu informan diambil dari pihak manajemen yaitu supervisor, dan tiga informan diambil dari pihak pekerja pada bagian produksi dengan jabatan line crew, inspector line 8 dan packer crew.

\section{Komitmen Top Manajemen}

Prioritas K3 pada PT. Coca-Cola Amatil Indonesia Central Java sudah sesuai dengan Undang-Undang Nomor 1 tahun 1970 pasal 14 bahwa perusahaan wajib menempatkan dalam tempat kerjanya semua syarat Keselamatan dan Kesehatan Kerja. Hasil penelitian pada PT. Coca-Cola Amatil Indonesia Central Java telah menerapkan berbagai peraturan dan perundang-undangan mengenai $\mathrm{K} 3$ untuk mendukung penerapan $\mathrm{K} 3$ di perusahaan. Peraturan perundang-undangan tersebut dijadikan regulasi, referensi maupun pedoman untuk perusahaan dalam berkomitmen terhadap K3.

Penyediaan perlengkapan K3 di PT. Coca-Cola Amatil Indonesia Central java sudah sesuai dengan Undang-Undang Nomor 1 tahun 1970 pasal 14 dan PERMENAKERTRANS Nomor Per. 08/Men/VII/2010 yang menjelaskan bahwa perusahaan wajib menyediakan perlengkapan K3 secara cuma-cuma kepada pekerjanya dan tamu dari luar perusahaan. Berdasarkan pernyataan informan pada PT. Coca-Cola Amatil Indonesia Central Java telah menyediakan perlengkapan $\mathrm{K} 3$ untuk pekerja maupun tamu yang datang ke area kerja. Hal tersebut dilakukan perusahaan untuk meminimalisir terjadinya kecelakaan pada pekerja maupun tamu/pihak dari luar perusahaan. Perlengkapan K3 yang disediakan perusahaan berupa ear plug, safety glass clear, safety glass for welding (goggle), earmuff, dusk mask, safety helmet, sarung tangan karet, sarung tangan kulit, masker kain, dan perlengkapan lainnya.

Berdasarkan Keputusan Menteri Tenaga Kerja dan Transmigrasi Republik Indonesia Nomor: KEP. 261/MEN/XI/2004 tentang perusahaan yang wajib melaksanakan pelatihan kerja, pada pasal 2 menjelaskan bahwa perusahaan yang wajib meningkatkan kompetensi pekerja/buruhnya melalui pelatihan kerja adalah perusahaan yang mempekerjakan 100 orang pekerja atau lebih. Berdasarkan hasil penelitian, PT. Coca-Cola Amatil Central Java pada tahun 2014 telah mempekerjakan 1.912 pekerja sehingga wajib untuk mengadakan pelatihan kerja yang bertujuan untuk meningkatkan kompetensi/pengetahuan pekerja. Berdasarkan pernyataan informan awal dan informan lanjutan, bahwa PT. Coca-Cola Amatil Central Java telah melaksanakan/mengimplementasikan undang-undang tersebut. Hal tersebut dapat dilihat dari keterangan informan lanjutan yang menyatakan pernah mengikuti pelatihan yang terkait dengan $\mathrm{K} 3$.

Pelaksanaan pengawasan K3 di PT. Coca-Cola Amatil Indonesia Central Java belum berjalan dengan konsisten. Pengawasan K3 di area kerja telah dilakukan oleh Dept. OHS, akan tetapi dalam penerapannya hanya dilakukan beberapa kali saja dalam satu bulan, hal tersebut dapat dibuktikan dari pernyataan informan lanjutan sebanyak satu informan (25\%) menyatakan kadang kala ada pengawasan K3 oleh Dept. OHS dan dua informan $(50 \%)$ menyatakan tidak adanya pengawasan K3 oleh Dept. OHS. Selain hal tersebut, dapat dibuktikan dengan studi dokumen bahwa hanya ada dua laporan dalam satu bulan (periode bulan agustus) yaitu laporan mengenai checklist inspeksi K3 No. Doc: OHS-MGM-D-F-001.4. Hal 
tersebut tidak sesuai dengan prosedur $\mathrm{ABg}$ sistem yang menjelaskan bahwa pengawasan K3 dilakukan setiap hari (daily).

PT. Coca-Cola Amatil Indonesia Central Java telah melakukan upaya peningkatan kinerja K3 dengan berbagai cara seperti training, rewarding, sosialisasi, kampanye, audit dan rule yang dijalankan. Ada beberapa pelatihan yang dilaksanakan pada tahun 2014 diantaranya yaitu pelatihan penggunaan safety belt/safety body hardness dan pelatihan tim pemadam kebakaran. Sedangkan rule yang dijalankan yaitu kebijakan nol toleransi (zero tolerance) dan awareness program CCAI OHS Golden Rules.

\section{Peraturan dan Prosedur K3}

Bedasarkan hasil penelitian, seluruh informan menjelaskan bahwa penting adanya peraturan dan prosedur $\mathrm{K} 3$ di tempat kerja, peraturan dan prosedur K3 tersebut dijadikan pedoman untuk melakukan pekerjaan. PT. Coca-Cola Amatil Indonesia Central Java telah menerapkan berbagai peraturan dan prosedur mengenai K3 yang dibuktikan dalam dokumen No. Doc CMS-LGL-D-F001.2. Akan tetapi pada penerapannya, peraturan dan prosedur $\mathrm{K} 3$ belum diterapkan dengan konsisten. Hal tersebut dilihat dari masih adanya pekerja yang melanggar/bekerja tidak sesuai dengan peraturan dan prosedur $\mathrm{K} 3$ seperti tidak memakai safety belt pada driver forklift. Adanya hal tersebut masih harus di evaluasi oleh pihak manajerial bahwa penting untuk menciptakan perilaku aman di lingkungan kerja.

Penyusunan peraturan dan prosedur K3 di PT. Coca-Cola Amatil Indonesia Central Java dilakukan oleh pihak manajemen dan perwakilan dari pekerja, hal tersebut sesuai dengan Peraturan Pemerintah Nomor 50 tahun 2012 pasal 9. Sedangkan sosialisasi peraturan dan prosedur K3 yang dilakukan perusahaan belum dilakukan secara merata kepada pekerja. Adanya sistem sosialisasi yang diadakan satu tahun sekali dan dengan sistem peserta (pekerja) yang ikut bergilir/bergantian sehingga masih dimungkinkan terdapat pekerja yang belum mengikuti kegiatan sosialisasi peraturan dan prosedur K3 di perusahaan. Perusahaan seharusnya melakukan sosialisasi tersebut lebih dari satu kali dalam setahun yang bertujuan agar mencakup semua pekerja.

Sikap perusahaan terhadap adanya pelanggaran peraturan dan prosedur $\mathrm{K} 3$ yang dilakukan pekerja, Dept. OHS memberikan sanksi/hukuman kepada pekerja berupa teguran lisan, surat peringatan, ataupun pemberhentian kerja. Adanya sanksi tersebut tidak sesuai dengan prosedur penerapan $\mathrm{ABg}$ sistem. $\mathrm{ABg}$ sistem tidak ada hubungannya dengan punishment (sanksi/hukuman). ABg sistem lebih mengedepankan komunikasi standar Keselamatan dan Kesehatan Kerja yang benar. Adanya prosedur $\mathrm{ABg}$ sistem tersebut, Dept. OHS harusnya melakukan tindakan pemberian informasi/himbauan kepada pekerja untuk melakukan tindakan yang sesuai dengan peraturan dan prosedur K3 yang diterapkan di perusahaan tanpa adanya sanksi/hukuman yang diberikan kepada pekerja.

\section{Komunikasi Pekerja}

PT. Coca-Cola Amatil Indonesia Central Java telah memberikan informasi mengenai K3 dan kecelakaan kerja pada pekerjanya, hal tersebut sesuai dengan Peraturan Pemerintah Nomor 50 tahun 2012 yang menjelaskan bahwa informasi 
mengenai K3 dan kecelakaan kerja dikomunikasikan kepada semua pihak di dalam perusahaan dan pihak terkait di luar perusahaan (misalnya: pemerintah).

Komunikasi dua arah yang dilakukan pihak manajemen dan pekerja di PT. CocaCola Amatil Indonesia Central Java, dari hasil penelitian menjelaskan bahwa Dept. OHS melakukan komunikasi yng baik dengan pihak manajemen yang dilakukan melalui email dan rapat-rapat. Sedangkan komunikasi langsung antara Dept. OHS dengan pekerja masih kurang. Masih kurangnya komunikasi langsung dengan pekerja mengenai permasalahan $\mathrm{K} 3$ dapat menjadikan pekerja melakukan tindakan yang tidak aman (unsafe action) yang dikarenakan ketidaktahuan pekerja mengenai pentingnya K3. Terciptanya budaya K3 di perusahaan dilandasi dari komunikasi yang baik antara pihak manajemen dengan pekerja serta komunikasi yang baik antara sesama pekerja. Komunikasi dua arah tersebut sesuai dengan tujuan ABg Sistem, bahwa salah satu tujuannya adalah menciptakan komunikasi dua arah antara pihak manajemen dengan pekerja.

\section{Kompetensi Pekerja}

Penunjukan ahli keselamatan kerja (Dept. OHS) pada PT. Coca-Cola Amatil Indonesia Central Java telah sesuai dengan Peraturan Menteri Tenaga Kerja, Transmigrasi dan Koperasi Republik Indonesia Nomor: PER.03/MEN/1978 yang menjelaskan bahwa ahli keselamatan kerja harus memenuhi syarat-syarat sebagai berikut: 1) Mempunyai keahlian khusus. 2) Telah mengikuti pendidikan oleh Departemen Tenaga Kerja Transkop. 3) Mengetahui ketentuan-ketentuan peraturan perundang-undangan perubahan pada umumnya serta bidang Keselamatan dan
Kesehatan Kerja pada khususnya. Ahli keselamatan K3 di PT. CCAI-CJ atau yang disebut dengan Dept. OHS memiliki latar belakang yang tidak sesuai yaitu lulusan D3 teknik mesin dan D3 ekonomi. Akan tetapi ahli keselamatan kerja di PT. Coca-Cola Amatil Indonesia Central Java sudah memiliki sertifikat K3 yang cukup memadai, yaitu sertifikasi ahli K3 umum dan audit SMK3 sehingga berkompeten terhadap permasalahan K3. Ruang lingkup Dept. OHS yaitu bertanggungjawab disemua area kerja termasuk area produksi, distribusi dan sales marketing.

Hasil penelitian mengenai pengetahuan pekerja terhadap resiko bahaya di lingkungan kerja, informan yang memiliki jabatan sebagai pekerja menyatakan bahwa mengetahui potensi bahaya yang ada di area kerjanya. Hal tersebut didasari dari pihak manajemen yang telah menjelaskan kepada pekerja mengenai potendi bahaya di lingkungan kerja.

Berdasarkan hasil penelitian, informan yang memiliki jabatan sebagai pekerja menyatakan bahwa mampu memenuhi peraturan dan prosedur K3 yang diterapkan di perusahaan. Akan tetapi pada implementasinya, pemahaman pekerja mengenai peraturan dan prosedur K3 tidak didasari dengan sikap beberapa pekerja yang masih melakukan tindakan pekerjaan yang tidak sesuai peraturan dan prosedur K3. Meskipun tindakan tidak aman yang dilakukan sekecil apapun, namun tetap akan memiliki potensi resiko terjadinya kecelakaan. Dengan demikian harus adanya upaya dari manajerial untuk menumbuhkan sikap/tindakan aman pada pekerja melalui pelatihan, sosialisasi maupun pengawasan sehingga tidak hanya mampu memenuhi dan memahami peraturan dan prosedur K3 akan tetapi 
mampu mengimplementasikan peraturan dan prosedur $\mathrm{K} 3$ tersebut dengan benar.

\section{Lingkungan Kerja}

Peraturan Pemerintah Republik Indonesia nomor 50 tahun 2012 pasal 7 menjelaskan bahwa perusahaan harus melakukan identifikasi potensi bahaya, penilaian dan pengendalian resiko. PT. Coca-Cola Amatil Indonesia Central Java sudah menerapkan peraturan tersebut, sehingga sudah dilakukannya identifikasi potensi bahaya di lingkungan kerja yang dilakukan dalam kurun waktu satu tahun sekali. Adanya perbaikan terus menerus yang dilakukan perusahaan bertujuan untuk meminimalisir potensi bahaya yang ada di lingkungan perusahaan. PT. Coca-Cola Amatil Indonesia Central Java melibatkan pekerjanya untuk mengidentifikasi potensi bahaya di lingkungan kerja melalui penyusunan HIRADC. Dimana masingmasing pekerja mengidentifikasi potensi bahaya dari masing-masing pekerjaannya.

Pelaporan yang dilakukan oleh perusahaan mengenai identifikasi potensi bahaya di lingkungan kerja, dari hasil pernyataan informan menjelaskan bahwa PT. Coca-Cola Amatil Indonesia Central Java telah melakukan pelaporan mengenai identifikasi potensi bahaya yang ditujukan kepada pemerintah dan pihak manajemen. Pelaporan tersebut bertujuan untuk mencari langkah perbaikan yang akan dilakukan guna meminimalisir resiko bahaya di lingkungan kerja. Dengan berkurangnya potensi bahaya maka peluang terjadinya kecelakaan kerja akan berkurang sehingga dapat tercipta kondisi zero accident.

Upaya yang dilakukan PT. Coca-Cola Amatil Indonesia Central Java untuk mengurangi potensi bahaya di lingkungan kerja yaitu Dept. OHS melakukan perbaikan secara terus menerus untuk meminimalisir potensi bahaya di lingkungan kerja. Selain itu Dept. OHS yang bertanggung jawab terhadap Keselamatan dan Kesehatan Kerja di perusahaan telah melakukan tindakan cepat tanggap apabila terdapat unsafe condition di lingkungan kerja. Hal tersebut bertujuan untuk mencegah terjadinya kecelakaan kerja.

\section{Keterlibatan Pekerja}

Hasil penelitian mengenai keterlibatan pekerja dalam penyampaian informasi K3, informan awal menjelaskan bahwa pekerja dilibatkan dalam perkembangan safety, setiap pekerja dapat menyampaikan semua mengenai aspekaspek safety seperti: potensi bahaya, kecelakaan kerja, near miss, dan semua hal mengenai K3. Informan lanjutan menjelaskan bahwa secara tidak langsung terlibat dalam penyampaian informasi mengenai $\mathrm{K} 3$, yang dilakukan pekerja yaitu: saling mengingatkan antara pekerja satu dengan pekerja lainnya tentang K3. Selain pelibatan pekerja dalam penyampaian informasi $\mathrm{K} 3$, pekerja juga dilibatkan dalam penyusunan program $\mathrm{K} 3$ di perusahaan.

Berdasarkan Peraturan Pemerintah Republik Indonesia nomor 50 tahun 2012 pasal 14 menjelaskan bahwa pengusaha wajib melakukan pemantauan dan evaluasi kinerja K3. Pemantauan dan evaluasi kinerja K3 melalui pemeriksaan, pengujian, pengukuran, dan audit internal SMK3 dilakukan oleh sumber daya manusia yang kompeten. Pada PT. Coca-Cola Amatil Indonesia Central Java pelaksanaan evaluasi dilakukan oleh pihak manajemen dan dibantu pihak pemerintah untuk mengevaluasi mengenai $\mathrm{K} 3$. Hal tersebut sesuai dengan peraturan pemerintah yang menjelaskan bahwa evaluasi kinerja K3 dilakukan oleh sumber daya manusia yang 
kompeten, pekerja tidk terlibat dalam evaluasi K3 di perusahaan.

Hasil penelitian mengenai pelibatan pekerja dalam pelaporan kecelakaan/kondisi berbahaya di area kerja, informan awal menjelaskan bahwa pekerja terlibat dalam pelaporan kecelakaan kerja dan kondisi tidak aman, akan tetapi dua pekerja menjelaskan bahwa meraka tidak terlibat dalam pelaporan kecelakaan dan kondisi berbahaya, sedangkan dua informan lanjutan lainnya menyatakan pernah melaporkan ke Dept. OHS pada saat terjadi kecelakaan atau kondisi berbahaya. Pekerja yang tidak melaporkan kondisi berbahaya ataupun kecelakaan kerja yang terjadi beralasan bahwa hanya terjadi kecelakaan kecil seperti lecet kena pecahan kaca, jatuh tersandung ataupun keadaan lainnya. Selain itu pekerja hanya sekedar memberitahukan kepada rekan kerjanya mengenai kecelakaan tersebut tanpa adanya pelaporan langsung ke Dept. OHS ataupun supervisornya. Selain itu dari data studi dokumen juga hanya didapatkan satu dokumen mengenai pelaporan nearmiss dan pelaporan tersebut bertanggalkan 28 April 2013. Upaya yang harus dilakukan perusahaan yaitu mengadakan pelatihan mengenai pelaporan kecelakaan yang ditujukan kepada pekerja.

Penerapan ABg Sistem pada PT. Coca-Cola Amatil Indonesia Central Java sudah dapat dilihat dari adanya komunikasi yang baik antara pekerja yang saling mengingatkan tentang pentingnya $\mathrm{K} 3$. Dengan adanya saling komunikasi tersebut maka ketika ada pekerja yang bekerja tidak sesuai peraturan dan prosedur $\mathrm{K} 3$ dapat menegur atau menyarankan pekerja lain untuk mengingatkan akan pentingnya mentaati peraturan dan prosedur K3. Komunikasi yang baik dapat menciptakan sikap kerja yang aman sehingga meminimalisir terjadinya kecelakaan kerja. Hal tersebut sesuai dengan prosedur penerapan $\mathrm{ABg}$ sistem.

\section{SIMPULAN}

Berdasarkan hasil penelitian dan pembahasan, gambaran dari evaluasi penerapan $\mathrm{ABg}$ sistem di PT. Coca-Cola Amatil Indonesia Central Java, penerapan $\mathrm{ABg}$ sistem belum dilakukan dengan maksimal dimana masih terdapat beberapa kendala pada indikator penilaian budaya K3. Beberapa kendala tersebut diantaranya: adanya pelaksanaan pengawasan $\mathrm{K} 3$ yang belum berjalan secara teratur, masih kurangnya konsistensi dalam penerapan peraturan dan prosedur $\mathrm{K} 3$, masih adanya pekerja yang melanggar peraturan dan prosedur K3, kurangnya komunikasi antara Dept. OHS dengan pekerja, serta kurangnya keterlibatan pekerja dalam pelaporan mengenai kecelakaan kerja/kondisi berbahaya.

Rekomendasi atau saran yang dapat diberikan kepada PT. Coca-Cola Amatil Indonesia Central Java mengenai kendalakendala pada penerapan ABg Sistem yaitu perusahaan mengupayakan peningkatan pengetahuan pekerja mengenai pentingnya K3 yang dapat diberikan melalui pelatihan, sosialisasi ataupun pemberian informasi $\mathrm{K} 3$ secara langsung. Sedangkan untuk Dept. OHS lebih berkomitmen untuk menjalankan kewajiban dan kewenangan sebagai ahli keselamatan dan kesehatan kerja sesuai dengan PERMENAKERTRANS No: Per.03/Men/1978 yang diantaranya yaitu melakukan pengawasan dan pelaporan mengenai K3.

\section{UCAPAN TERIMA KASIH}


Ucapan terima kasih kami sampaikan kepada Dekan Fakultas Ilmu Keolahragaan Dr. H. Harry Pramono, M.Si, Ketua Jurusan Ilmu Kesehatan Masyarakat Irwan Budiono, S.KM., M.Kes, dosen pembimbing Evi Widowati S.KM., M.Kes, serta seluruh pihak PT. Coca-Cola Amatil Indonesia Central Java yang terlibat dalam penelitian ini.

\section{DAFTAR PUSTAKA}

Andi dkk, 2005, Model Persamaan Struktural Pengaruh Budaya Keselamatan Kerja pada Perilaku Pekerja di Proyek Konstruksi, Jurnal Teknik Sipil, Volume 12, No. 5, Juni 2005, hlm. 127-136.

Health and Safety Executive, 2013, Health and Safety in Manufacturing in Great Britain 2013, HSE, Inggris.

Humas dan Protokol Pemerintah Kabupaten Semarang, 2014, Pengusaha Dihimbau Utamakan Keselamatan Kerja, Kamis, 06 Februari 2014, (http://www.semarangkab.go.id/ utama/ berita/ kegiatan-pemerintahan/ 1570 pengusaha-dihimbau-utamakan-keselamatanpekerja.html)

Jamsostek, 2012, Annual Report Building on Strengths Toward a Employment BPJS, PT. Jamsostek (Persero), Jakarta.

Menteri Tenaga Kerja dan Transmigrasi, 2004, Keputusan Menteri Tenaga Kerja dan Transmigrasi Nomor: Kep. 261/Men/XI/2004 Tentang Perusahaan yang Wajib Melaksanakan Pelatihan Kerja, Menteri Tenaga Kerja dan Transmigrasi Republik Indonesia, Jakarta. Kerja dan Transmigrasi Nomor: Per. 08/Men/VII/2010 Tentang Alat Pelindung
Diri, Menteri Tenaga Kerja dan Transmigrasi Republik Indonesia, Jakarta.

Occupational Health and Safety, 2013, Aktif Berbagi (ABg) Sistem, PT. Coca-Cola Amatil Indonesia Central Java, Kabupaten Semarang.

2013, Data Kecelakaan Kerja, PT. Coca-Cola Amatil Indonesia Central Java, Kabupaten Semarang.

Pemerintah Republik Indonesia, 1970, UndangUndang Republik Indonesia Nomor 1 Tahun 1970 Tentang Keselamatan Kerja, Presiden Republik Indonesia, Jakarta.

2012, Peraturan Pemerintah Republik Indonesia Nomor 50 Tahun 2012 Tentang Penerapan Sistem Manajemen Keselamatan dan Kesehatan Kerja, Presiden Republik Indonesia, Jakarta.

Sugiono, 2010, Metode Penelitian Pendidikan Pendekatan Kuantitatif, Kualitatif, dan R\&D, Alfabet, Bandung.

Tarwaka, 2008, Keselamatan dan Kesehatan Kerja Manajemen dan Implementasi K3 di Tempat Kerja, Harapan Press, Surakarta.

The Coca-Cola Company, 2012, Global Reporting Initiative (GRI) Report 2011/2012, The CocaCola Company.

U.S. Bureau of Labor Statistics, 2013, Number of Fatal Work Injuries 1992-2012, U.S. Department of Labor, U.S.

Wieke dkk, 2012, Pengaruh Budaya Keselamatan dan Kesehatan Kerja (K3) Terhadap Kinerja Proyek Konstruksi, Jurnal Rekayasa Sipil, Volume 6, No. 1, hlm. 83-95.

Winarsunu T, 2008, Psikologi Keselamatan Kerja, Universitas Muhammadiyah Malang Press, Malang. 